\title{
Saberes campesinos para la crianza de la papa en las comunidades aimaras del altiplano, Puno
}

\section{Juan Inquilla Mamani}

(iD) https://orcid.org/0000-0003-2540-9091

Universidad Nacional del Altiplano-, Perú.

jinquilla@unap.edu.pe/ inquilla@hotmail.com

\section{Jorge Apaza Ticona}

iD https://orcid.org/0000-0002-9085-4354

Universidad Nacional del Altiplano, Perú.

japazaticona@unap.edu.pe/ apazat@hotmail.com

RESUMEN

El objetivo de este artículo es ofrecer un análisis de los saberes ancestrales de los aimaras sobre la crianza de la papa e identificar las diversas formas de conversación que ellos establecen con las señas agroecosistémicas. El estudio se basa en una perspectiva metodológica etnográfica cualitativa que utiliza técnicas de entrevista cara a cara y observación participante. Los resultados de la investigación evidencian que, en las comunidades andinas de Puno, la crianza de la papa está vinculada estrechamente con el comportamiento climático, por tanto, las conversaciones con las señas agroecosistémicas son constante en las distintas etapas del ciclo agrícola.

Palabras clave: aimaras, comunidades, sabiduría campesina, crianza de la papa, señas. 


\section{Peasant Wisdom for the Nurturing of the Potato in the Aimara Com- munities of Altiplano, Puno}

\section{ABSTRACT}

The purpose of this article is to offer an analysis of the ancestral knowledge of the Aimara about the nurturing of the potato crop, and to identify the different forms of conversations with the agroecosystemic signs. The methodological perspective is ethnographic and qualitative, based on face to face interview technique and participant observation. The results of the research show that, in the Andean communities of Puno, the breeding of the potato is closely linked to climate behavior, therefore, the conversations with the agroecosystemic signs, is constant in response to the different stages of the agricultural cycle.

Keywords: Aimaras, communities, peasant wisdom, breeding of the patata, signs. 


\section{INTRODUCCIÓN}

La naturaleza en los Andes ofrece una multitud de potencialidades en plantas alimenticias y medicinales. Las familias agricultoras consideran que en este pacha (término que se traduce como «cosmos» en el mundo andino), todo se considera como seres vivos y vivificantes: la naturaleza, deidades y humanos, todos tienen chacra. Por eso dicen: «El cerro es mi protector, es mi achachila (abuelo y autoridad), es mi uiwiri (el que cría)». De la tierra dicen: «Es mi pacha mama (madre criadora), es mi abuela que me da vida, ellos siempre me acompañan en la crianza de la chacra». La comunidad de humanos está formada por chacareros de las achachilas. Las deidades, también son criadas por los humanos. Por eso ellos hacen la ofrenda ritual que consiste en una dulce misa o aytu misa (rituales de conversación con las deidades). Así, en el mundo andino se convive en reciprocidad y armonía con las tres colectividades naturales: humanos, deidades y naturaleza. La comunidad humana es aquella forma de vida colectiva conformada por pueblos, parcialidades, comunidades campesinas, y acompaña a la naturaleza y a las deidades en la crianza y regeneración de las diferentes formas de vida. Por su parte, la comunidad de deidades está compuesta por los cerros protectores conocidos como achachilas (cerros tutelares, apachetas), ríos, manantiales y lagunas, que son los facilitadores y armonizadores de la crianza de las demás colectividades. Por último, la comunidad de la naturaleza es aquella en la cual se recrean las chacras criadas por la comunidad de deidades y humanos. La población andina comprende que la chacra es el núcleo que anuda a las tres comunidades, por lo que se considera una cultura agrocéntrica por excelencia.

El altiplano peruano presenta gran diversidad climática y la agricultura campesina depende principalmente de condiciones climáticas ambientales, como precipitaciones pluviales, heladas, granizadas, sequías, inundaciones, etcétera. En este contexto, las formas de crianza de los diferentes cultivos que desarrollan las familias campesinas están basadas en la cosmovisión andina tradicional. Los aimaras conceptúan la chacra de cultivos como una comunidad, donde el origen reproductivo de la mayoría de las plantas es la libre polinización para favorecer la 
diversidad y perpetuar su descendencia en toda su potencialidad. Entre los seres vivos existe la complementariedad macho/hembra, donde concurren diferentes especies de vegetales, animales y tipos de suelos que se relacionan entre sí para beneficio mutuo.

Los propósitos de este artículo son analizar los saberes ancestrales de los aimaras sobre la crianza del cultivo de papa e identificar las diversas formas de conversación que establecen con las señas agroecosistémicas en las diferentes etapas del proceso productivo. El contenido de este artículo está estructurado de la siguiente manera: el primer apartado describe el proceso metodológico empleado en la investigación; el segundo presenta un análisis de los saberes ancestrales de la crianza del cultivo de la papa en el altiplano peruano; el tercer apartado aborda las diversas formas de conversación que establecen los aimaras con las señas agroecosistémicas en las distintas etapas del proceso productivo, y finalmente el cuarto presenta las conclusiones de la investigación.

\section{SABIDURÍA ANCESTRAL DE LOS AIMARAS EN LA CRIANZA DE LA PAPA}

Para Rengifo (1998), «en la pachavivencia todo es sagrado; por tal razón, lo que prima es el cariño y respeto en cada momento de la vida» (p. 3). En las comunidades aimaras no hay acto, lugar, persona, cosa ni fecha que no sea sagrado y sugiera culto. Para Del Campo (2006), el hombre está en estrecho contacto con su medio natural: todo es motivo de cariño, celebración y respeto. No solo es motivo de celebración ritual a la pachamama sino también las semillas, el barbecho, la siembra y el consumo de alimentos. Como dice Grillo (1996), el mundo aimara es un mundo vivo en el que «todo cuanto aquí existe tiene vida, los hombres, los animales, las plantas, los suelos, las aguas, los vientos, los cerros. Se vive en un mundo sensitivo y emotivo, es un mundo de crianza» (p. 54).

La cosmovisión tradicional del hombre andino se manifiesta en su mitología, su religión y su ética. Esta da el sentido al quehacer económico, a la tecnología y al trabajo. Es un significado que va más allá de los valores económicos y que alcanza el nivel de los valores afectivos, humanos y religiosos. Esta cosmovisión define y sanciona también el modo particular en el que el hombre andino se relaciona con su medio natural. Además, la reciprocidad dinámica es también una unidad determinante de la cosmovisión andina. Según Arnold (2004):

El mundo, en su unidad constitutiva, es dinámico eternamente vivo y articulado por un sinfín de «nervios», simbólicos, alimentado por una infinidad de redes 
de arterias y venas cósmicas. Todo en el mundo es interdependiente y recíproco. Es acentrismo. El mundo andino no tiene centro, propiamente hablando. En el sistema de reciprocidad universal nada ni nadie dominan (p. 23).

Según Valladolid, (1993) «el espacio andino es producto de más de 10000 años de vivencias en los Andes y su vertiente oriental, la población estuvo estrechamente relacionada a la crianza de plantas y animales» (p. 99). Se conceptúa al universo como una chacra en la que se crían mutuamente la naturaleza, las deidades y el hombre. Por lo tanto, no es propicia otra forma de crianza que no sea propia de esta zona. El campesino admite con respeto su obligación de criar a un ser vivo: no se limita a manejar cultivos, sino que esto incluye comunicarse con las plantas.

La región andina es el centro de origen, variación, dispersión y crianza de un gran número de especies, variedades, ecotipos o razas de plantas alimenticias y medicinales. Dice Ishizawa (2003) que «en el contexto mundial, la diversidad biológica se encuentra localizada en los territorios de los países denominados "pobres", particularmente los de alta montaña, y quienes quieren hacer uso de los "recursos genéticos" existentes en ellos» (p. 9).

En la vivencia andina emana una diversidad de atributos en paridad o equivalencia: nadie es menos en toda la colectividad. Las jerarquías no tienen lugar. Se concibe la conversación en el mundo andino como una relación establecida entre todo lo que existe: puesto que todo está vivo, entonces todas las formas de vida hablan (Valladolid, 1993). El lenguaje no es atributo de la comunidad humana únicamente. Compartir en los Andes es realizarse. Todos nos realizamos en el hecho de dar, de recibir, de participar comunitariamente. Estar en el mundo andino es criar y compartir los frutos de la chacra. La redistribución es la capacidad que tienen todos los componentes de la naturaleza de distribuir y no acumular, permitiendo que la equivalencia se recree y actualice socialmente.

Al respecto, don Santos Vilca Cayo nos presenta su testimonio:

En los Andes todos/ como los animales silvestres y domesticados/ aves/ las plantas silvestres,/ los vientos/ las nubes/ la granizada/ el sol/ la luna/, todos somos chacareros desde siempre/ ellos nos da señas/, nos avisa lo que va pasar y lo que no va pasar/ por eso conversamos siempre y con mucho respeto/

El atributo de los vivos no es sentido por los jaqis (personas) como la personificación de un espíritu vivificante y trascendente en una piedra, en una papa o en un río que, al hacerse presente en el ritual, muta o cambia de modo mágico la naturaleza de lo inerte en una sustancia dotada de vida. Tampoco es un modo 
metafórico de denominar las cosas. Cuando un jaqi dice: «La pachamama (madre naturaleza) es mi madre», lo hace de forma honesta, haciendo una analogía con su madre biológica. Simplemente, para él la pachamama es su madre. Según Grillo (1993):

El mundo andino es un mundo vivo y vivificante en el que, sin embargo, lo relevante no es la vida en sí, que es una abstracción, sino más bien los seres vivos concretos que lo habitan en simbiosis, con su gran diversidad y complicación, la gran multitud de formas de vida, los innumerables procesos orgánicos que alberga. Se trata de un mundo-animal en cuyo seno todo cuanto existe a su vez también es vivo. Considérese que en la cultura andina no solo son seres vivos los hombres, los animales y las plantas sino también los suelos, las aguas, los ríos, las quebradas, los cerros, las piedras, los vientos, las nubes, las neblinas, las lluvias, los montes o bosques y todo cuanto existe (p. 23).

En las comunidades aimaras la vivencia comunitaria se expresa en el ayllu. En teoría, la noción de ayllu nos aproxima al sentido más profundo de humanidad. Lambert (1980) dice que, es:

... la relación de familiaridad y descendencia que existe entre los miembros de un grupo humano vinculados consanguíneamente y que viven en un territorio determinado. La parentela consanguínea se refiere a las vinculaciones entre parientes y afines relacionados en grados variables con la misma persona (p. 13).

Según Albó (2011), suma qamaña en aimara quiere decir «habitar o vivir en determinado lugar o medio en armonía». Más allá de las muchas interpretaciones posibles del suma qamaña o del «vivir bien», esto nos muestra un modo de pensar fuertemente arraigado. Qamasiña es «vivir bien con alguien». Implica intercambio, reciprocidad y convivencia, incluida la convivencia con la naturaleza (pp. 134-137). El suma qamaña contiene, por lo tanto, un fuerte componente ético, una valoración y aprecio del otro distinto y una espiritualidad.

Estas reflexiones nos muestran que hay que aprender y desaprender para caminar bien en la comunidad. Suma qamaña no es una utopía por construir. Según Polanyi (1992),

las experiencias y prácticas civilizatorias alternativas al capitalismo hacen del buen vivir una utopía realizada y realizable; y en la medida que se puede convertir en una herramienta que profundice la crítica de la actual civilización y ofrezca propuestas concretas de acción, podría contribuir para «una gran transformación» en términos planeados (p. 157). 


\section{CALENDARIO AGROFESTIVO DE LA CRIANZA DE LA PAPA}

El calendario agrario se puede definir como un sistema de escala temporal utilizado por la sociedad para medir convenientemente el tiempo según las necesidades de la vida social. La historia del calendario es tan antigua como la civilización misma. Beltrán (2003) sostiene que todas las comunidades han tenido un calendario para regular las actividades agrícolas y religiosas (p. 78). En los Andes, la agricultura era la principal actividad de las culturas altiplánicas; el cultivo de la tierra exigía que las técnicas básicas de siembra, riego y cosecha se realizaran según un cronograma anual o calendario agrícola que fue elaborado a través de la experiencia que durante miles de años acumularon los preíncas e incas.

La práctica astronómica en los Andes está ligada a su génesis cultural, debido a la necesidad de este conocimiento para la actividad agrícola y de domesticación de la naturaleza. Su presencia en la historia andina es relevante. Entre los testimonios logrados por las investigaciones arqueoastronómicas, son de resaltar las observaciones astronómicas preíncas e incas, tales como los alineamientos intersolsticiales y estelares, los calendarios iconográficos y de sombras, los fechados angulares y los espejos astronómicos como herramientas dentro de una práctica social y ritual permanente. Todo esto indica claramente que la cultura altiplánica reconocía la característica cíclica del tiempo y utilizaba estos conocimientos para beneficio de la población.

La manera de pensar el tiempo y el espacio es una variable cultural y un atributo constitutivo de la identidad particular de un grupo social, por cuanto condensa un discurso sobre el mundo y las cosas. La percepción del desarrollo temporal, mediante la cual se aprehende intuitivamente la noción abstracta de tiempo, no es posible más que en el ordenamiento de un acontecimiento en relación con otro, definiendo un corte entre un antes y un después, evaluando la duración y distanciando dos momentos (Bonte e Izard, 1996). El calendario se graficó en forma ovoide y está dividido por etapas. Aquí se explica de la siguiente manera: 


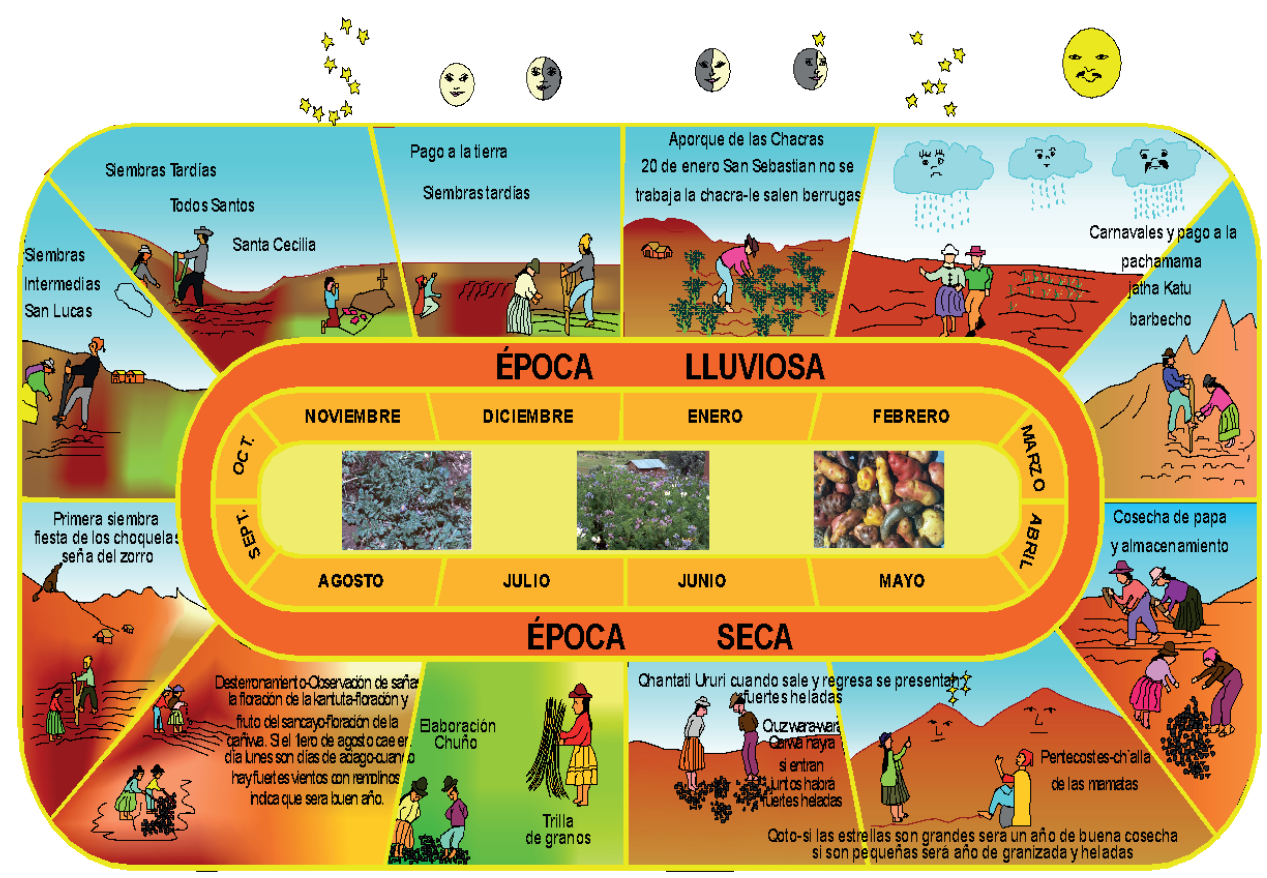

Elaboración propia, 2018.

Primera etapa. Está distribuida en los meses del año.

Segunda etapa. Está distribuida la época agrícola (autipacha $=$ época seca, jallupacha $=$ época lluviosa), tomando los meses del año. La primera época corresponde al periodo abril-noviembre y la segunda empieza a mediados del mes de noviembre y dura hasta el mes de abril del año entrante.

Tercera etapa. Corresponde a la participación y conversación con todas las familias de la colectividad natural con las señas, labores de crianza y fiestas rituales. Cuarta etapa. En la cosmovisión aimara, la constelación, estrellas, astros son considerados como familia y siempre están presentes en la crianza de la papa.

\section{LABORES DE CRIANZA DE LA PAPA}

En los meses de marzo, abril y mayo se realiza la actividad de roturación de la tierra, y en mayo se realiza el ritual de ch'alla (ritual a la madre tierra) de quepamamatas (productos agrícolas). Entre junio y agosto llega la segunda etapa de preparación de suelo. En aimara le dicen qutirpa o wille (desterronamiento), 
y además, se observan las primeras señas de las plantas con su floración, trilla y almacenamiento de productos. En los meses de octubre y noviembre se inicia la siembra grande de cultivo de papa. Diciembre y enero corresponden a las jornadas de los primeros aporques y también se realiza el ritual de despacho de granizo y helada en las siguientes fechas: 1 de enero, 20 de enero y comadre. En febrero se realiza el último aporque o kawa.

En la visión andina, particularmente en la cultura aimara, hablar de un conocimiento homogeneizado no tiene lugar, porque las características de cada zona son diferentes y variadas, cada agricultor tiene sus propios saberes y prácticas de criar la chacra. Por lo tanto, los indicadores o las señas son para cada sector o lugar agroecosistémico. La crianza de papa demanda una serie de actividades que deben realizarse durante la campaña agrícola. Al respecto, nos testimonia don José Roque Roque de 47 años de Titilaca:

/ para la chacra de papa/ el terreno se prepara desde el mes de marzo con qhulli (roturación de terreno)/ para iniciar esta actividad/ previamente se realiza un pequeño ritual de permiso a la pachamama/ con llampu (cebo de llama)/ $\mathrm{coca} / \mathrm{vino} / \mathrm{y}$ se entierra en la parte derecha de la parcela el $k^{\prime}$ inthu/ luego con bastante fe y cariño/ hacemos la respectiva akulli a las yuntas, es decir/ a las uysus" (chaquitaclla)/también los participantes pijchan coca y beben alcohol para tener la fuerza/ nosotros le decimos walak'i/ los momentos de descanso/, en este espacio/ de igual manera/ también pijchamos todos la coca y alcohol/ nuestras herramientas es bien respetado/ nadie puede tocar ni pueden rayar ni hacer señales con las uñas/ porque puede romperse la punta de la reja.

Don Agapito Ccosi Quispe, de cincuenta años, nos cuenta sobre la preparación de terreno:

/ aquí en nuestra comunidad/ hay dos formas de roturación de tierra/ uno con uysu y otro con la yunta/ nuestros abuelos/ para iniciar cada labor agrícola siempre realizaban un $k^{\prime}$ 'inthu o chillt'a/ este acto para nosotros es respeto mutuo/ porque la madre tierra nos da de comer y también nos cuida a cada uno de nosotros/ por eso, para iniciar el barbecho o roturación de suelo/ primeramente todos juntos nos saludamos/ luego se realiza un $k^{\prime}$ inthu invocando a las divinidades que participen en este acto/ cada participante invoca con seis hojitas de coca y la depositan en mesa de k'inthu/a esto lo acompañan con vino/ qoa (planta silvestre aromática)/llampu (cebo de llama)/ esto lo entierramos en el medio de la parcela/ finalmente pasamos la buena hora entre todos y después pijchamos, / tomamos alcohol luego iniciamos a roturar el suelo entre tres personas/ dos varones llamados qhulliris y una de apoyo de bajar los terrones llamada ateqiri o pinchiri/ inicia de abajo hacia arriba, siempre del lado derecho/ 


\section{a) K’upaña (desterronamiento)}

Esta actividad es la segunda labor de preparación de terreno. Consiste en destruir finamente los terrones uno por uno; además, el desterronamiento cumple la función de nivelación del suelo. En esta actividad participan todas las familias y se utiliza la herramienta muy especial ch'awa, que está hecha en forma «T», su mango es de palos de qolli y su mazo es de fierro. También se utiliza zapapico para levantar o aflojar los terrones. Al respecto nos cuenta don Pablo Sosa Mamani, de sesenta años, de Platería, de la siguiente manera:

/la época del desterronamiento se inicia desde el mes de agosto hasta el mes de setiembre/ con las primeras lluvias que se presenta durante esas fechas/ cuando está mojado/ facilita mayor avance del trabajo y menos esfuerzo/ una vez terminado el desterronamiento/ se recoge y se amontona los champas/ rastrojos en diferentes lugares de la parcela/ después se quema y la ceniza se utiliza como abono en el momento de la siembra/ esta operación se llama jap'uña, actividad delicada a fertilizar el suelo/ pero la generación de hoy está olvidando estas prácticas/ porque lo ven por facilísimo y realizan con el tractor/ el año pasado tuve la oportunidad de hacer desterronar con el tractor pero no me resultó bien/ había bastante terrones en el momento de la siembra/ entonces no es recomendable/ por otro lado también estamos perdiendo la conversación con las señas/ que nos avisan para la próxima campaña/

Don Aurelio Roque Mamani, de 49 años, del sector Jantha, nos dice lo siguiente:

/esta actividad de k'upaña es muy importante/ porque de ella depende la producción de papa/por eso se realiza los días buenos/no hay que desterronar en los días de aciago/ luna nueva/ porque el suelo o terreno se puede malograrse hasta por tres años/ esta actividad se realiza en las faenas nomás en caso de mi familia/ en este labor se conversa con el sapo/ nidos de ratón/ en donde nos avisan la presencia de lluvia/ helada y la producción de papa/

\section{b) Sataña (siembra)}

Es la actividad más importante de la crianza de la papa, porque de ella dependerá el éxito o el fracaso de la producción. En esta labor conversan con las señas y señaleros, para el inicio de la campaña agrícola del año en curso. Observan las señas desde su inicio de floración hasta la fructificación. Por otro lado, las señas son para un lugar determinado; no es homogéneo, sino que sus comportamientos 
son diferentes. Al respecto nos cuenta doña Isabela Tapia Ccosi, de 35 años, de Titilaca:

/ en el tiempo de la siembra, hay que levantarse de muy tempranas horas, no hay que dormir hasta tarde/ porque las semillas introducidas no pueden germinar en su totalidad y otros se quedan dormidos/ esta práctica se viene practicando desde nuestros ancestros/ siempre mi abuela nos decía/ hay que levantarse de muy temprano los días de la siembra de papa/ para sacar las semillas siempre hay que rezarnos y las semillas que sean alegres hay que sobarnos con cebo de llama llampul

Doña Isidora Mamani Ccosi, de cuarenta años, nos cuenta:

/ para ir a la siembra de papa con mi familia acostumbramos llevarnos harta fiambre/también nos llevamos los recados rituales como/vino/ coca/llampu/ incienso/ qoa/ para dar la ofrenda a la santa tierra pachamama/ todos vamos bien cambiados/ flores puestas en el sombrero/ para iniciar la siembra primeramente se amarra la yunta y luego se marca una línea recta para hacer el surco/ cuando ya está en la mitad/, de manera de descansar la yunta/ todos nos juntamos alrededor de la semilla amontonada para efectuar el ritual de piwi/ este acto consiste en bajar dos montones de papa cada uno/ previamente pidiendo una oración silenciosa y frotándose la mano/ luego se separa par en par/ cuando queda las tres papitas/ significa la siembra de papa es momento y las mismas semillas se challa con vino/ llampu y flores y se entrega a la madre tierra desciendo que esta es la madre de toda las semillas y se encarga/ a partir de hoy tú eres la madre que cuidarás de las heladas y granizo y de las enfermedades/ así desciendo se entrega a la pachamama y se entierra en el medio de la chacra/

\section{c) Thumi (aporque)}

Esta labor cultural es realizada por cinco a seis personas entre familias. En lengua aimara lo llaman thumiña (aporque) y para realizarla utilizan la herramienta llamada en lengua nativa liwjana, y en aimara, isichuraña, es decir, dar la ropa o abrigar a la planta. Se inicia alrededor de las fiestas de navidad, cuando la planta tiene una altura de 20 a $30 \mathrm{~cm}$, aproximadamente, y termina en enero del año siguiente, esto con la finalidad de que la planta aumente su crecimiento y follaje. Además, se le considera como una persona que se viste con harta ropa. Las familias campesinas de algunas localidades dan al aporque qawa dos formas: 
-Maykipa qawaña. Consiste en dar la tierra en forma intercalada en cada surco de papa. Se hace antes de la fiesta de reyes, generalmente cuando la planta está por botar las primeras floraciones. Esta práctica se realiza con la finalidad de que el suelo se mantenga húmedo cuando hay la escasa presencia de lluvia.

-Purapa qawaña. Es otra forma de hacer el aporque; se realiza después de la fiesta de reyes y se terminan los surcos que se ha dejado en el anterior aporque. Por otro lado, se trabaja aquellas chacras que están ubicadas en las partes planas (pampa), cuando hay mayor presencia de lluvia. Al respecto, tenemos los siguientes testimonios. Doña Rosa Ccosi Yucra, de sesenta años, de Acora nos dice:

/ en esta pacha (cosmos) todos somos agricultores y vivimos ayudándonos unos a los otros/ hasta los sueños nos acompañan en la crianza/ en aymará decimos uywasiri puraw utjastanja/y yo les cuento acerca de sueño que $m i$ avisa para realizar el aporque/ una noche esta pensando cómo estarán mis chacras/ ya va llegar la fiesta de reyes/ así desciendo me acosté/ resulta que me soñé con mis hijos/ que en mi sueño mis hijos eran vestidos de ropas totalmente rotas y una de mis hijas caminaban calatas y al ver a ellos me avergonzados/y mi despierto no era así / esto mi indica de que me chacra es mi hijo, en mediato boy a visitar a mis chacras y me encuentro apenado $\mathrm{y}$ triste/ las estolones de las papas estaban enverdeciendo y algunos chacras están llevados por los fuertes llujmas (riachuelos)/ entonces mi sueño era de verdad/después el mismo día con mi familia hemos ido a efectuar el aporque/ mi mamá siempre nos hablaba/las chacras son nuestros hijos e hijas en donde nosotros debemos criar como una hija/ hay que vestir, cuidar de las enfermedades y dar el abrigo en su tiempo/ pero en momento ella es nuestra madre que nos cría también/ cuando ya recogemos la cosecha/

Doña Luisa Ccosi Mamani de 65, de Acora, nos cuenta:

/ los aporques se realiza los días buenos, pasados dos días de luna creciente/ en las fiestas de reyes no se realiza esta actividad porque los tubérculos pueden desarrollar encima del tallo nomás/ y además puede producir mayormente con verrugas/ esas días es favorable para realizar aporques de cultivos de habas, porque los frutos va hacer de pie a cabeza bien cargado/ las qawas/ aporques/ se debe terminarse para la fiesta de Candelaria/ cuando no lo terminamos, la mamita Candelaria suele preguntar/ dónde están los pañales/ en qué vas a envolver tus hijos/ y la papa llorando/ sabe quejarse/ de mí nadie se recuerda/ entonces la Mamita Candelaria la encarga/ anda a otra familia/ ellas te crían con cariño/ yo le castigaré a esta familia/ de ahí siempre en 2 de febrero cae la helada/ 


\section{d) Llamayuña (cosecha)}

Esta actividad empieza en los meses de marzo y abril, en la orilla de lago: la siembra qhuchi, pero la cosecha grande se inicia a partir del 15 de abril y dura hasta las fiestas de San Isidro Labrador (15 de mayo). Hay años que se prolonga hasta la primera semana de junio. Para esta actividad se utiliza la herramienta llamada liwjana, confeccionada por los mismos agricultores. La amarran con lazos de cuyunta (cuero de vaca o llama cortado en forma de cinta), una reja de punta y el kuti. Es de qolli, un arbusto silvestre que tiene forma de "Y". Para iniciar el escarbo, desde tempranas horas de la mañana las familias campesinas realizan el ritual de jiwqecha (sahumerio) en el medio de la chacra, con la finalidad de llamar a las ánimas de las papas. La cosecha siempre se realiza comunitariamente. Al respecto tenemos los siguientes testimonios. Doña Juana Ccosi Flores nos dice:

/ la cosecha siempre se hace con varias familias/ para esto primero hay que hacer una fogata en el medio de la chacra con bastante fe y cariño/ invocando a las divinidades de la chacra con vino/ coca e incienso/luego se empieza la cosecha jugando el qatati (arrastre), para que las papitas se alegren y para tener bastante cosecha. En esta actividad no se lleva el ganado vacuno, porque al mojar las ánimas de las papas se pueden espantarse/ la cosecha se hace en qaña/ que se hace en surco/ intercalada/

\section{e) Choqe j’atachaña y imaña (selección y almacenamiento)}

La selección de semilla, en aimara ch'oqi jatachaña, se realiza una vez terminada la cosecha y faltando unos días para la fiesta de Pentecostés «espíritu» (fecha movible, puede ser en mayo y junio). Las papas se clasifican en tres: las papas de tamaño grande, llamadas munta ch 'oqi, que se destinan para el autoconsumo; los tubérculos medianos y sanos se separan como semilla, y las papas pequeñas se deshidratan para preparar chuño (papa deshidratada). Con referencia a los tubérculos destinados al chuño, los extienden a campo abierto en la época de helada, en lugares llamados ch'uñawis, donde hay mayor incidencia de helada.

En cuanto a choqi imaña, los pobladores de la zona de estudio siguen realizando las mismas experiencias vividas por nuestros ancestros, que consisten en guardar las papas destinadas para consumo y semillas en forma de phina en una esquina de la vivienda. Para guardar estos tubérculos, primero se extiende en la base algunas hierbas, como la muña y paja. A continuación, se depositan los tubérculos. Finalmente, se tapan con las mismas plantas. Esta práctica tiene como finalidad conservar el tamaño y el peso. Al respecto, nos cuenta doña Rosa Ccosi Yucra, de sesenta años, de Platería: 
/ la selección de semillas se realiza unos días antes de la fiesta de espíritu/, se separa en tres partes/ las papas grandes para consumo familiar/ los medianos para las semillas y gusanados, fraccionadas y muy pequeños son destinados para la elaboración de chuño y para moraya. Yo guardo mis semillitas de papa en una esquina de mi habitación con bastante muña en phina, extendiendo sobre la base una capa de muña/ y sobre ella cubro con paja ahí pongo mis semillitas, para que no sea afectando la gusanera/ polveo con cal procesado en toda phina, huyo y luego tapo con muña y paja por encima. Después no lo toco hasta que llegue la época de siembra.

\section{f) Elaboración de chuño y almacenamiento}

Esta actividad consiste en trasladar los tubérculos destinados a la elaboración de chuño a los chuñawis, es decir, a aquellos lugares que tienen mayor incidencia de la helada. Para su procesamiento, primero se hace la limpieza del área según la cantidad de papa; luego, se extienden las papas en parejo. Después, a las siete u ocho de la noche, se rocía con agua a los tubérculos extendidos y se dejan de dos a tres noches. Una vez que los tubérculos están deshidratados en su totalidad, se pisan en pequeños montones para quitar todo el líquido que se forma dentro de la cáscara de papas, con el fin de deshidratar. Después, nuevamente se extiende a la helada y en seguida se hace el proceso de alliquipaña, es decir, voltear de un lado a otro y luego secar. Cuando está seco, se refriega una y otra vez para quitar el resto de las cáscaras. Luego se realiza el proceso de venteo, con la finalidad de separar en dos partes los chuños enteros y los partidos. Después de terminada la actividad, se realiza un pequeño ritual de agradecimiento a la tierra pacha mama con todos los recados rituales, como incienso, coca, vino, etcétera.

\section{FORMASDECONVERSACIÓNCONLASSEÑASAGROECOSISTÉMICAS DE LOS AIMARAS EN EL ALTIPLANO PERUANO}

Para las familias aimaras, el saber se expresa en la sincronización de la interacción de los seres (humanos, naturaleza y deidades); es decir, es la sintonía y empatía con la pacha (cosmos), la cualidad de compartir la sabiduría entre todos los que habitamos en la pacha o mundo local. Aquí, entonces, la crianza y la vivencia es recíproca: todos tienen chacra, todos son criadores; por lo tanto, las familias aimaras están ligadas en la conversación permanente con las señas o indicadores naturales, para saber si la campaña agrícola va a ser adelantada, intermedia o tardía. Además, estos elementos de la colectividad natural indican que en la presente campaña habrá periodo lluvioso o periodo seco. 
Observan a las plantas, animales, sueños, como indicadores para la crianza de los cultivos de papa. Por otra parte, las fiestas rituales también forman parte de la conversación con la naturaleza y se expresan espiritualmente con alegría, reciprocidad, respeto, como expresión de cariño y crianza mutua. Participa tanto la comunidad humana como las comunidades de la naturaleza: todos juntos comparten esta fiesta de ceremonia ritual y se realiza únicamente en fechas agrofestivas.

\section{a) Indicadores de la planta}

Las familias agricultoras de la zona de estudio conversan con una diversidad de indicadores para la actividad agrícola, porque en los Andes el clima es variado y denso. Por tal razón, los criadores observan y conversan constantemente con las señas, y cada una de ellas muestra diferentes comportamientos para predecir el año.

Cantuta (Cantua buxifolia). Esta planta crece en las laderas del cerro y también es una planta ornamental que habita en las casas de las familias. Se observa como seña su floración y su fructificación. Existen dos variedades de cantuta: una es de floración roja y otra es de floración amarilla; la primera es seña para papa dulce y la segunda es seña para papa amarga. Al respecto, nos cuenta don Pablo Sosa Mamani, de 68 años, de Platería:

/ en mi comunidad existe dos variedades de cantuta: cantuta de floración roja y amarrilla./ ambos son señas para cultivo de papa/ la planta de cantuta roja es señas para el cultivo de papa dulce y se observa las tres momento de floraciones de la cantuta de flor roja/ y para papa amargo la floración de la cantuta amarilla su fructificación de frutos/ para el presente años 2016-2017 la primera floración está pasmada/la segunda y la última floración fructificó bien/ no está pasmada/ esto nos indica que la siembra de papa va hacer intermedio y tardía/ porque la siembra adelantada puede ser castigada por la presencia de veranillo/ por otro lado también se observa la orientación de la flor/ cuando las flores están mayormente cargado en el lado del lago/ se puede decir que la producción de papa va estar en las partes abrigadas/

Thola (Lepidophyllum qudrangulare). Esta planta se ubica en las partes altas y es otro indicador para el cultivo de papa. Se observa la intensidad de su floración y su fructificación: cuando sus frutos son como las bayas o tulco de la papa y son afectadas por la helada, es señal de que en la campaña agrícola en curso habrá la presencia de helada. Al respecto, nos cuenta don Modesto Ccosi Quispe, de setenta años, del sector Charca Central: 
/ esta planta empieza a florecer en el mes de agosto para la siembra adelantada/ setiembre para la siembra intermedia y tardía/ se observa los tres momentos de floración/ cuando la primera floración llegado a formar la baya en la parte alta de la planta la cual/ indica la siembra de papa va ser adelantada/ y cuando las dos últimas floraciones están pasmadas/ es señal de que las últimas siembras va ser castigada por la helada, y cuando las dos últimas llegó a fructificar bien/ es para año de abundancia producción de papa/

Lorenzo Mamani Condori, de sesenta años, del sector Jantha, nos dice:

/ yo siempre observo esta planta para cultivo de papa/ cuando su floración está bien blanquito y su fruto ha fructificado en su mayoría/ es señal para buen año y de abundancia cosecha/

Sank'ayu (fruta silvestre - Lobivia boliviana). Es otra planta observada por los comuneros. Crece en las partes altas, en las laderas del cerro, y hay años que suele habitar en las pampas; se observa su floración y fructificación. Al respecto, nos cuenta don Agapito Ccosi Quispe, de cincuenta años, del sector Charca Central:

/ la floración de sank'ayu nos indica para la producción de papa/ así también para la presencia de lluvia y se observa los siguientes detalles/ hay años que el sank'ayu se encuentra ubicada encima del nivel del suelo/ esto nos indica para el año de lluvia, pero otros años el sank'ayu se encuentra hundida por debajo del nivel del suelo/ esto implica que en el presente campaña habrá poca lluvia y las chacras de papa se siembra en los terrenos húmedas/por otro lado/ cuando las flores está mayormente orientado al lado del lago la cual indica en la presente año la siembra de papa será en zonas de riberas del lago/ otro detalle es cuando las primeras floraciones de sank'ayu están pasmado y las dos últimas están en proceso de fructificación/ la cual nos indica la siembra de papa va ser intermedia/

Qariwa (árnica - Senesio clivicolus). Esta planta se encuentra en las partes abrigadas y se observa durante el tiempo de floración, en los meses de agosto y setiembre. Es seña para cultivo de papa cuando su flor está muy cargada de color amarillo, pues indica una mayor producción. Se observan los tres momentos de floración y maduración; cada indicador es para un determinado lugar. Al respecto, nos manifiesta don Máximo Apaza Aro, de 81 años, de Pilcuyo:

/ para el presente año, esta planta empezó a florecer a mediados del mes de setiembre y noviembre/ la primera floración era ralo, la segunda y la última floración está bien cargado y bien amarillento la cual nos indica que la siembra de papa va ser intermedia y en las partes abrigadas/y termina su 
fructificación/ es decir/ su fruto es como algodón/ en aymará se denomina jheyasiwa/ y cuando cae con el movimiento del viento en el mismo lugar, esto nos indica que la producción de papa es seguro en esa parcela/y cuando el viento se lo lleva puede ser que le afecte la helada o granizo/ por eso yo acostumbro sembrar en diferentes momentos y en diferentes lugares/ cuando hay helada/, granizo se llevará una parte/ nomás/ y en otras lugares siempre hay la cosecha.

Layu (trébol silvestre). Es una planta silvestre que se ubica en cualquier parte de las comunidades, pero su mayor concentración está en las parcelas descansadas (purumas). Se observa como seña en las jornadas de roturación del suelo (qholly). Cuando las raíces de esta planta se parten en forma longitudinal, es señal para buen año de cosecha. Al respecto nos cuenta doña Bacilia Ticona Quispe, de 81, años de Ilave:

/ esta planta se observa en el mes de marzo y abril en el momento de preparación de suelo/ cuando esta planta aparece repartida en forma longitudinal en los terrones es señal para un buen año y buena cosecha de papa/ hay años que esta planta no se parte/ si no se quedan enteros en los mismo terrones/ la cual nos indica que en la presente campaña habrá la presencia de helada/

\section{b) Señas de los animales}

Jamp'atu (sapo - Bufo spinolosus). Se observa su presencia, la coloración de su cuerpo, y su lustrosidad en la época de desterronamiento (agosto y setiembre): cuando se presentan gordos y brillosos es señal de buen año y también avisa que ya es momento de la siembra, en cambio cuando son flacos y de color amarillo indican un año de escasa lluvia. Al respecto nos manifiesta don Andrés Mamani Mamani, de setenta años, comunero del sector Machacmarca:

/ el sapo es otro indicador para la crianza de cultivo de papa este año/ juntamente con mi familia/ hemos ido a desterronar en el lugar Janthapampa/ en el cual/ al iniciar el desterronamiento/ hemos visto tres sapos bien gordos/ pareciera que estaban preñados y eran bien brillosos y de color negro/ esto nos indica que el año va ser bueno y habrá la cosecha de papa y también habrá la lluvia/ cuando vemos en las chacras/ se respeta/ no se debe matar/ porque este animal es dueño de la chacra/ además cuando nos visita a la casa hay que recibir con mucho cariño y se challa con vino/ porque es signo para tener plata/ $a$ veces se encuentran dormidos en los lugares de almacenamiento $p h i-$ nauyo/ lo cual nos indica que en la presente campaña va haber cosecha y hay que sembrar/ nomás/ en cualquier parte/ 
Don Pablo Mamani Mamani nos dice:

/ que el año pasado afectó a mi chacra mucha gusanera/ entonces/ con mi hijo hemos recolectado sapos en bastante cantidad y la llevamos a la chacra de papa/ en horas de la tarde los soltamos en cada surco tres sapos/ después de dos noches visitamos a la chacra/ dándonos con la sorpresa que no encontramos ningún sapo/ este animal se habian juntado en mi patio dentro de una piedra plana (misa qala)/ esto mi indica que ese año he cosechado bastante papa.

Jama T'anqa (escarabajo pelotero). Este insecto aparece con la presencia de las primeras lluvias y se observa el tamaño de la bola de estiércol que lleva y los montoncitos de tierra que saca para enterrar dicha bola de estiércol.

Al respecto nos comenta doña Isidora Mamani Ccosi, de cuarenta años, comunera del sector Charca Central:

/ este insecto lleva su bola de estiércol tamaño grande y mediano y las tierras que ha sacado para enterrar es granulado y amontonado en un solo sitio en forma de romas de piedra/ es signo de buen año/ habrá la producción de papa/ pero hay años solamente lleva pequeñas bolitas de estiércol/ lo cual nos indica que la producción de papa va ser regular y habrá la ausencia de lluvia/

Pancataya (insecto díptero - Bothynus sp.). Es otro insecto que da señales para la crianza en la chacra. Se observa su presencia y su coloración. Al respecto, nos manifiesta don Maximo Apaza Aro, de Pilcuyo:

/ cuando este insecto suelen aparecer en bastante cantidad y de color amarillento antes que entre el sol y cuando molesta a los animales, a la gente es señal para la ausencia de lluvia.

Sutuwalla (lagartija). Son crías del lagarto, habita en las romas de las piedras o en las piedras planas y se observa su colita en los meses de setiembre a noviembre. Al respecto, nos cuenta don Pablo Sosa Mamani:

/ yo les contaré los detalles que se observa de esta lagartija/ cuando sus colitas no están quemados por la helada/ implica buen año/ y cuando están cortados y secados significa que habrá mayor presencia de helada/

Asiru (culebra). Es otro reptil que avisa de la presencia de lluvia y sequía. Vive en todas partes. Para efectos de seña, se observa la coloración de su piel, su presencia y cambio de piel.

Al respecto, nos comenta don Agapito Ccosi Quispe: 
/ reptil nos conversa para la presencia y ausencia de lluvia y se observa los siguientes detalles/ cuando su piel es color negruzco y se encuentra en las pampas/ significa la presencia de lluvia y la siembra se realizar en las parte laderas/ y cuando es de color amarillento y su presencia es en el cerro, lo cual nos indica ausencia de lluvia. $Y$ las siembras se efectúan en las parcelas húmedas.

Chooqa (focha - Fulica americano). Esta ave vive en el lago y las familias de la zona observan los siguientes detalles: conformación y ubicación de su nido, número de huevos que deposita y número de polluelos que logra empollar. Al respecto nos dice don Rolando Pomari, de setenta años, de Tilali:

/ cuando su nido está ubicado en la zona alta con bastante totora, / implica que será año de lluvia/ y cuando está construido el nido al nivel del agua significa que el año pasará con escasa lluvia/ cuando los huevos termina en par (cuatro, seis y ocho) nos indica poca producción/ pero cuando es impar (tres, cinco y siete) y cuando logra empollar impar/ es buena seña/ se dice es piwi/ habrá la producción de papa/

Pariwana (flamenco). Se observa su presencia, cantidad, y la concentración en manadas que aparecen de lejos como si estuvieran pisando chuño. Al respecto nos cuenta don Venancio Arrazola, de 69 años, del sector Charca Central:

/ estas aves suelen llegar en el mes junio/ cuando las pariwanas se encuentran en abundancia y cuando están moviéndose como si estuvieran pisando chuño/ es señal que el siguiente año la producción de papa será muy buena y habrá bastante para para hacer chuño/

Liquichu (ave centinela - Ptilesclys respelndes). Esta ave es observada por los agricultores según los siguientes detalles: la concentración y ubicación de su nido, número y coloración de los huevos. Al respecto nos cuenta don Modesto Ccosi Quispe:

/ cuando esta ave pone su huevo en las orillas del lago/ en bofedales/ es signo de ausencia de lluvia/ y cuando deposita sus huevos en las partes altas/ es decir encima del techo de una casa y su nido está compuesta con estiércol de ovino/ y su huevo tiene pequeñas rayitas/ implica para año de lluvia con presencia de truenos y habrá la cosecha de papa/ para que no haya la producción, esta ave suele formar su nido con dinero/ raíces de grama dulce/ esto indica presencia de helada y sequía/

Qiwlla (gaviota). Se observa su presencia y en cantidad, se presenta en la época de barbecho. Al respecto don Máximo Apaza nos cuenta: 
/ cuando esta ave llega en el mes de agosto en mayor número/ es señal para buen año y habrá la producción de cultivos/ y cuando nos visitan en el momento de preparación de suelo «kutirpa» el terreno/ esto nos indica en la presente campaña agrícola buena producción de papa/

Tiwula (zorro). Este animal es otro indicador para la crianza de la papa y se observan los siguientes detalles: su aullido, posicionamiento y presencia. Al respecto, doña Bacilia Ticona Quispe nos cuenta:

/ cuando este animal aúlla en el mes de agosto (fiesta de Asunta) encima de una piedra y en su aullido se atora/ significa que ya es hora para la siembra de la papa qhuchi/ siembra adelantada/ y cuando se escucha su aullido en la fiesta de San Miguel/ con las mismas características es para buen año/ para años de escasa producción/ el zorro aúlla antes y después de las fechas indicadas anteriormente y además su aullido es salla/ es decir/ no se atora/ significa que es para mal año/

\section{c) Señas meteorológicas}

Los pobladores de la zona de estudio conversan también con elementos meteorológicos para la crianza de la chacra, así como las nubes de las cordilleras, la presencia de lluvia en las fiestas de San Juan de Dios (8 de marzo) o San José (19 de marzo), el viento. Al respecto tenemos los siguientes testimonios:

Qenaya (nube). Don Pablo Sosa Mamani nos cuenta sobre el comportamiento de las nubes:

/ cuando hay mayor presencia de nube en el lado del lago/ particularmente en las islas de Taquile/ Capachica/ Amantani/ es signo de presencia de lluvia/ además/ cuando la nube sale del lado este con dirección al oeste también es signo de la presencia de lluvia/ cuando la nube está bien clara en el día/ es decir solea fuerte/ es signo de presencia de granizo/

Lluvias. Hay años en que se presentan lluvias inusuales, y sobre todo en fechas festivas. Estos comportamientos climáticos tienen significados para el agricultor andino. Don Agapito Ccosi Quispe dice:

/ yo quiero contar sobre la fiesta de San Juan de Dios y San José de la siguiente manera/ cuando cae la lluvia en la fiesta de San Juan de Dios (8 de marzo) y San José (19 de marzo)/ significa para buen año y habrá lluvia. Cuando se adelanta de llover antes de dos o tres días significa año de siembra adelantada/ y cuando se retrasa implica que en el año habrá poca lluvia/ 
Urpu (neblina). Al respecto, nos manifiesta don Juan Chino Calli de Ilave:

/ cuando este fenómeno entra antes que salga el sol al lago/ es signo para buen año/ pero cuando el sol agarre en las tierras cultivables/ es señal para la presencia de helada/ el anteaño pasado/ urpu (neblinas) ganó al sol/ cuando ya estaba en medio del lago/ recién salía el sol/ entonces en ese año hubo bastarte producción de papa/

Nos sigue contando:

/ cuando hay presencia de lluvia y se forma un pequeños chorros, en ahí se observa/ al llover deja como pequeños globitos que en el idioma aymará se denomina jalluj utachaiwa/ lo cual nos indica que la lluvia va seguir lloviendo con mayor frecuencia/

Granizo. Existen dos tipos de granizo: chhujaña (granizo mediano) y chijchi (granizo grande). Se observa su presencia en el mes de marzo, por San Juan de Dios. Al respecto, nos cuenta don Agapito Ccosi Quispe:

/ para mí/ el 8 de marzo/ día de San Juan de Dios es un día muy importante para la campaña agrícola/ si el año va ser lluvioso o seco/ si cae precisamente en esta fecha chhujaña (granizo mediano)/ es señal de que habrá bastante producción de cultivos de papa y quinua/ y cuando cae chijchi (granizo granulado) nos indica que habrá presencia de granizo en mayor intensidad/

Viento. Se observa su presencia en diferentes épocas y momentos durante el año. Al respecto, nos cuenta don Pablo Sosa Mamani:

/ el viento empieza a correr a partir de los primeros días de mes de junio/ normalmente el día 29 de fiesta de San Pedro y San Pablo/ se observa la pelea de dos vientos/ viento del lado suni y viento del lado del lago/ cuando el viento del lago gana al viento de suni es signo de año de lluvia y cuando gana el espacio el viento de suni es signo de poca presencia de lluvia/

Kurmi (Arco iris). Es otro indicador para la ausencia y presencia de lluvia. Al respecto nos cuenta doña Bacilia Ticona, de 81 años, de Pilcuyo:

/ cuando el kurmi (arco iris) se forma a una altura de 50 metros del nivel del suelo/ esto significa para que se despegue la lluvia/ cuando está ubicado al lado del lago es para continuar la lluvia/ y cuando se ubica en los cerros nos indica ausencia de lluvia/ 


\section{d) Señas de astros}

Es otro elemento natural que se guían las familias para la crianza de la chacra. Se observa la salida y entrada de las pléyades y el caminar de la pacha jawira (vía láctea).

Pléyades (chejje). Estas pléyades están conformadas por siete estrellas. En aimara se denomina qotowarawara o cabrilla. Se observa la salida del conjunto de estrellas: cuando salen brillantes y grandes, es signo de buen año y cuando sale opaco y las estrellas son menudos, lo cual nos indican que en la presente campaña no habrá lluvia y será año de producción de animales. Por otro lado, hay años que las pléyades se regresan y vuelve a salir después de una semana. Es signo de kutimara, año de siembra en la misma parcela. Al respecto nos cuenta Pablo Sosa Mamani:

/ estas constelaciones se observa para año de lluvia y abundancia cosecha fecha que aparece/ para años adelantados esta constelación sale antes y alrededor de la fiesta del 24 de junio y cuando son brillosos y de tamaños grandes nos señala que la siembra va ser adelantada y habrá cosecha de papa/ hay años esta constelación suele salir y se regresa nuevamente y descansa unos días/ esto significa que la siguiente campaña se puede sembrar la papa en la misma parcela del año pasado en aymará se dice kutimaraniwal

Don Máximo Apaza nos dice:

/ cuando la cabrilla sale alrededor de la fiesta de espíritu y 24 de junio (San Juan) es señal para la presencia de helada/ cuando sale con brilloso y son grandes/ nos indica que habrá helada para la elaboración de chuño/ $a$ partir de esa fecha nosotros llevamos las papitas destinados para chuño a los lugares denominados chuñawis/

Aciago. Se refiere cuando el sol está con anillo de arco iris; es señal que no es adecuado para la siembra de tubérculos (papa), sin embargo, es favorable para la siembra para forraje de ganado. Al respecto, las familias agricultoras dicen «el sol está enfermo» y no es recomendable trabajar la chacra en ese día, porque el suelo pierde su fertilidad hasta cinco años. Al respecto nos cuenta don Francisco Vilca:

/ cuando el sol está con anillo de arco iris/ nosotros decimos el inti tata (sol)/ está enfermo y en ese día no se realiza la chacra/ ni se prepara el suelo porque la tierra se malogra por tres a cinco años/ por eso nosotros siempre observamos la salida del sol y la entrada/ y de igualmente de la luna/ 
Urt'a (luna llena). Se refiere a cuando la luna está saliendo del oriente y el sol está por ocultarse en occidente. Los aimaras dicen kjapjtiwa intimpi phajsimpi («encuentro entre el sol y la tierra»), por lo tanto en ese día no se remueve la tierra, porque la tierra se malogra por siete años. Al respecto nos manifiesta don Aurelio Roque Mamani:

/ en luna llena (urta) y luna nueva (jairi) wawapajsi/ qara no se realiza la chacra/ porque se malogra por siete años/ no hay producción de ningún cultivo/ por eso nosotros no realizamos esos días la chacra/ ni preparamos la tierra/

Celaje (qara pacha). Los comuneros de la zona de estudio observan también el celaje. Al respecto don Francisco Vilca nos cuenta:

/ cuando el sol está en el horizonte oeste y se ve color amarillo anaranjado/ es señal que se alejará y descansará la lluvia/ cuando el cielo es color azulino y las estrellas son brillosos es signo de presencia de helada/

Relámpago. Es otro indicador para crianza de cultivo de papa. Al respecto nos cuenta don Agapito Ccosi Quispe:

/ el relámpago, en aymará se denomina qejoqejo achachila/ nos castiga cuando la comunidad humana estamos en desunión/ cuando cae a un animal/ es señal para mal año y habrá poca lluvia/ cuando el relámpago cae a la casa y no hay fallecidos es para buen año/

\section{e) Señas de sueños}

El hombre andino se guía también por los sueños para la crianza de cultivo de papa. El agricultor campesino interpreta, a través de los sueños, las diferentes actividades relacionadas con la crianza de la papa. Al respecto nos cuenta doña Rosa Ccosi Yucra:

/ yo les contaré de mi sueño/ una noche me acosté pensando cómo estará mis chacras en la parte alta del cerro y mañana iré a dar la tierra aporque/ y resulta que en mi sueño se mueren mis hijitos/y otros eran vestidos de ropas viejas/ todo traposo/ esto $m i$ indica que mis chacras han sido afectada por fuertes riachuelos llujmas/ por otro lado cuando me sueño con los cerdos/ es signo de presencia de helada y cuando recibo en mis sueños bastante pan por las personas ya fallecidas y las mismas eran bien borrachas/ es señal para un buen año y presencia de lluvia/

Isabel Tapia Ccosi agrega: 
/ en mi sueño recojo manzanas/ higo, / durazno en una canasta/ luego me las como con mi familia/ es señal para buena cosecha de papa, tendremos la cosecha para todos. Cuando se quema pan en el horno/ significa habrá la presencia de helada/ para el presente año me soñé que todas las noches estoy cargando me wawa (hijo) y cada vez se enfermaba/ esto implica de que en el presente año habrá la presencia de helada/ entonces hay que sembrar la papa en las partes que no tienen helada/

Nos sigue contando:

/ a veces para año de lluvia sé soñarme que en cada fiesta veo borrachos y son mayor cantidad/ es signo de año de lluvia y para la presencia de granizo/ sé soñarme con los militares que están enfrentando la guerra con otros militares y personas que pelean con piedras/ esto significa la presencia de granizo/

\section{CONCLUSIONES}

En las comunidades aimaras están vigentes las conversaciones con las diversas señas y señaleros (indicadores climatológicos) en el proceso de la crianza de la papa. Según las experiencias de los aimaras, existe un calendario agrofestivo de cultivo de papa, estructurado en cuatro etapas en los diferentes meses del año. Cada lugar, además, posee sus propias señas y señaleros; estas indican o anticipan al agricultor sobre los tiempos y momentos de la siembra, así como el lugar donde se debe sembrar primero, o retrasar la siembra. Estas señas son animales, plantas y comportamientos de los astros, que con anterioridad a la época de la siembra de la papa se comportan de una determinada manera, que el agricultor lee e interpreta.

En la cosmovisión andina, el término crianza está íntimamente relacionado con la vida familiar y social que se establece entre la madre y los hijos. No solo se trata de producir papa: se trata de criar una vida como la madre que cría un hijo. El trato entre agricultor y su chacra está por encima de una relación eminentemente económica. En esta forma de vida que llevan los agricultores andinos aimaras subyace una filosofía de vida más armoniosa, horizontal y comunicativa. Es decir, el agricultor que cría papas establece un diálogo permanente con los seres que protegen (deidades) con el fin de solicitarles los medios para criar en su seno. Porque todos tienen vida: hombres, naturaleza y deidades.

El agricultor andino dialoga permanentemente con la madre tierra para solicitar, pedir y suplicar, muchas veces a través de ritos, como el pago a la Pachamama (ellos los llaman ayt'avis), acompañados con sus oraciones y rezos. 
Esta respetuosa conversación también se realiza con los agentes climáticos que deciden la suerte de la chacra: las heladas, el granizo, el viento (los llamados hermanos jaqes o chicotillos). Una vez sembrada la chacra, el agricultor entabla un afectuoso diálogo con los tres agentes perturbadores del clima, los que podrían ocasionar un desastre: los tres hermanos chicotillos que controlan las heladas, el granizo y los vientos. Este diálogo involucra la realización de ritos especiales en cada época.

Mediante la conversación con las familias agricultoras de la zona, se logró un registro de saberes de crianza señas y secretos para la crianza de cultivo de papa, porque estos saberes no se hablaron en este tiempo, sino que desde siempre nuestros ancestros han conversado con nuestro medio natural y asimismo se ofrecían las ofrendas para la crianza de los cultivos.

\section{REFERENCIAS BIBLIOGRÁFICAS}

Alanoca, Vicente (2013). La presentación de la categoría del suma qamaña, «buen vivir», en la cultura aimara. En Otros horizontes de vida, diálogo sobre desarrollo y buen vivir. La Paz: ISEAT.

Arnold, Simón Pedro. (2004). Ritualidad y cambio, el caso aymara. Lima: IDEA/ CEP.

Beltrán, Patricia (2003). Las nociones de tiempo y espacio en el calendario ritual de Cariquima Liminar. Estudios sociales y humanísticos, 2, vol i, diciembre, 76-86. México, D.F.: Centro América San Cristóbal de las Casas

Bonte, Pierre y Izard, Michael (1996). Diccionario akal de etnología y antropología (primera edición en francés, 1991). Madrid: Akal.

Del Campo, Alberto (2006). Mal tiempo, tiempo maligno, tiempo de subversión ritual. La temposensitividad agrofestiva invernal. Revista de Dialectología y Tradiciones Populares, 1, vol. LXI, 103-138. Sevilla: Universidad Pablo Olavide.

Grillo, Eduardo (1993). La cosmovisión andina de siempre y la cosmología occidental moderna. Lima: PRATEC.

Grillo, Eduardo (1996). Caminos andinos de siempre. Lima: PRATEC.

Ishizawa, Jorge (2003). Kawsay Mama madre semilla. Criar diversidad en los Andes del Perú. Desafios globales, 3. Lima: PRATEC.

Kusch, Rodolfo (1962). América profunda. La Paz: Hacette.

Lambert, Bernd (1980). Bilateralidad en los Andes. En Parentesco y matrimonio en los Andes. Lima: PUCP. 
Polanyi, Karl (1992). La gran transformación - Los orígenes políticos y económicos de nuestro tiempo. México, D.F.: Fondo de Cultura Económica.

Rengifo, Grimaldo (1996). El Ayllu. Lima: PRATEC.

Rengifo, Grimaldo (1998). Crianza ritual de semillas. Lima: PRATEC.

Valladolid, Julio (1993). Agroastronomía andina. En Desarrollo o descolonización en los Andes. Lima: PRATEC.

Valladolid, Julio (1993). Las plantas en la cultura andina y en occidente moderno. En Desarrollo o descolonización en los Andes, segunda versión. Lima: PRATEC. 